\title{
OS BENEFICIÁRIOS DO PROGRAMA BOLSA FAMÍLIA E O MERCADO DE TRABALHO: UMA ANÁLISE BIBLIOGRÁFICA SOBRE O "EFEITO PREGUIÇA"
}

\author{
THE RECIPIENTS OF BOLSA FAMÍLIA PROGRAM AND THE LABOR MARKET: AN ANALYSIS \\ OF THE "LAZINESS EFFECT"
}

\section{Luciene Oliveira Prosperi', Lincoln Frias ${ }^{2}$}

RECEBIDO: 28/08/2018 | ACEITO: 13/08/2019

DOI: $10.5902 / 2317175834492$

\section{RESUMO}

Uma das críticas recorrentes ao Programa Bolsa Família (PBF) é o receio de que os beneficiários trabalhem menos do que trabalhariam se não recebessem a transferência de renda, caracterizando o "efeito preguiça". Este artigo tem como objetivo apresentar um estudo sobre o comportamento laboral do beneficiário do Programa Bolsa Família, visando esclarecer o impacto do benefício sobre a sua disposição para o mercado de trabalho. A pesquisa foi elaborada a partir de pesquisa bibliográfica, apresentando um levantamento geral sobre o perfil social do beneficiário do programa social e sobre o mercado de trabalho para pessoas com esse perfil. $O$ estudo possibilitou a elaboração de uma revisão bibliográfica. Após a introdução, a segunda seção apresenta o perfil do beneficiário do PBF, objetivando caracterizar o público alvo do programa, enquanto a seção seguinte resume os principais estudos econométricos sobre a participação dos beneficiários no mercado de trabalho. Os estudos analisados não encontraram evidências do "efeito preguiça" ou apenas efeitos muito pequenos em alguma subpopulação, por exemplo, uma redução pequena no número de horas trabalhadas pelas mães. Outro resultado é a constatação de que estes estudos oferecem poucas informações sobre as opções de trabalho para a pessoas pobres e extremamente pobres. Por isso, a quarta seção se dedica a uma tarefa mais sociológica: a contextualização do mercado de trabalho para essa população, abordando o microempreendedorismo como uma porta de saída para as situações de trabalho degradante. Portanto, conclui-se queo receio de que o PBF faça com que os beneficiários trabalhem menos não é um fundamento consistente para criticar o programa.

Palavras-chave: Programa Bolsa Família. Efeito preguiça. Mercado de trabaIho. Microempreendedorismo.

\footnotetext{
1 Bacharel em Biblioteconomia pela Universidade Federal de Minas Gerais, é especialista em Docência no Ensino Superior (UNIS MG) e Gestão Pública Municipal (UFJF), e mestre em Gestão Pública e Sociedade (UNIFAL). Atualmente é bibliotecária da Prefeitura Municipal de Três Pontas e professora do Centro Universitário do Sul de Minas.

2 Professor da Universidade Federal de Alfenas (Unifal, campus Varginha). Graduado, mestre e doutor em Filosofia pela UFMG. Recebeu o Grande Prêmio Capes de Teses em 2012.
} 


\section{ABSTRACT}

The Bolsa Familia Program (PBF, Programa Bolsa Familia) is often criticized based on the fear that the recipients would work less than they would in the absence of the cash transfer, what is commonly called "laziness effect". This paper is a review of the literature on this subject. After the introduction, the second section analyses the PBF's recipient profile, characterizing the program's target population, whereas the next section summarizes the main econometric studies on the beneificaries' participation in the labor market. The reviewed studies did not find evidences of the laziness effect - or found only very small effects in some subpopulation, for example, a small reduction in the work hours of mothers. Another result is the confirmation that those studies offer few information about the work opportunities available to poor and extremely poor people, what is essential for the analysis of the variations on the beneficiaries' labor supply. Hence the fourth section endeavors a more sociological task: the contextualization of the labor market for the poorer individuals, including the idea of microentrepreneurship as an exit door to degrading work conditions. Therefore, the fear that the PBF would provoke a labor reduction among the recipients is not a good ground for criticizing the program.

Keyword: Bolsa Família Program; Laziness effect; Labor Market; Microentrepreneurship.

\section{Introdução}

O Programa Bolsa Família (PBF) é uma transferência de renda direta, não contributiva e condicionada que foi concebida com os objetivos de minimizar os impactos da pobreza e evitar sua reprodução intergeracional, através da promoção de segurança alimentar, nutricional e da inclusão social (BRASIL, 2013b). Para atingir tais objetivos o programa repassa recursos financeiros e promove o acesso aos serviços públicos de educação, saúde e assistência social para membros das unidades familiares pobres e/ou extremamente pobres beneficiárias do programa.

Para Campello (2013) ao final de 10 anos de existência, o Programa Bolsa Família apresentou resultados relevantes na redução da desnutrição e da insegurança alimentar e superou as ações parciais e desarticuladas anteriores a sua existência, nas condições de saúde das crianças, ocasionando o encolhimento da mortalidade e da desnutrição infantil. Na educação, o PBF reduziu o número de crianças fora da escola, cumprindo as metas de redução da evasão e da regularização da trajetória escolar, permitindo melhores médias de frequência e aprovação das crianças das famílias beneficiárias.

Criado a partir da Lei n. 10.836/2004, o Programa Bolsa Família unificou os programas e ações de transferências de renda preexistentes, sendo configurado como uma transferência de renda voltada para a população pobre e extremamente pobre. O programa prevê atenção especial para as crianças das famílias beneficiárias que devem ser acompanhadas pelos serviços de saúde e mantidas na escola como contrapartida para o recebimento do benefício. 0 desenho do programa conta com critérios públicos que focalizam a população alvo. A focalização e as condicionalidades fazem com que beneficiários e Estado coparticipem, garantindo a fruição dos serviços básicos de educação e de saúde pelas crianças, no intuito de atacar os determinantes da pobreza de forma que as gerações futuras estejam equipadas para superá-la. 
OS BENEFICIÁRIOS DO PROGRAMA BOLSA FAMÍLIA E O MERCADO DE TRABALHO:

UMA ANÁLISE BIBLIOGRÁFICA SOBRE O "EFEITO PREGUIÇA"

Desde a sua criação, o programa é questionado sobre a possibilidade do repasse do recurso financeiro influenciar negativamente o comportamento laboral dos beneficiários adultos. O objetivo deste trabalho é analisar essa crítica, segundo a qual, ao repassar o benefício para os usuários, o programa influencie a oferta de trabalho destes, fazendo com que deixem de trabalhar ou trabalhem menos, o que é chamado de "efeito preguiça" (CAMPELLO, 2013). Esta análise parte do pressuposto que o potencial beneficiário do programa está disponível para o trabalho, muito embora, mesmo com a criação de 20 milhões de empregos formais e queda no desemprego apresentadas por Fonseca e Fagnani (2015) ele não é assimilado pelo mercado de trabalho ficando à mercê de formas de trabalho precárias e sem garantias sociais. Ainda assim, Campello (2013) afirma que os beneficiários do PBF trabalham. Afirmação que Medeiros, Britto e Soares (2007) reforçam ao confirmar que o valor do benefício corresponde a $11 \%$ na renda dos beneficiários, valor que não é suficiente para que haja o desincentivo ao trabalho e concluem que o argumento do desestímulo ao trabalho é mais baseado em preconceitos do que em evidências empíricas, apontando o caráter falacioso do argumento do "ciclo da preguiça", que seria gerado pelo PBF. "Talvez seja desnecessário enfatizar que, geralmente, os pobres não deixam de trabalhar por decisões livres e espontâneas, e sim porque não têm emprego em condições aceitáveis. " (MEDEIROS; BRITTO; SOARES, 2007, p. 16).

O artigo está organizado visando apresentar dados quantitativos e qualitativos que possam embasar a análise proposta sobre a crítica de que o beneficiário do PBF possa deixar de trabalhar como consequência do recebimento do benefício. Na primeira seção será exposto o perfil do beneficiário do programa, com destaque para questões geográficas e de gênero. Na segunda, as pesquisas sobre os efeitos do benefício do PBF sobre a oferta de trabalho, o que se fará entender de forma mais clara na terceira seção. Nela são apresentadas as características e fragilidades do mercado de trabalho para os trabaIhadores pobres, acompanhado de um estudo sobre o trabalho como inclusão social e os meios de promove-lo através do microempreendedorismo. $E$, finalmente, a conclusão na qual todos os dados corroboram para a percepção de que há muito mais a se discutir acerca do trabalho para pobres do que as pequenas (e justificáveis) variações de oferta de trabalhos entre os beneficiários.

\section{0 perfil do beneficiário do Programa Bolsa Família}

Estudos confirmam que a maior parte da população adulta beneficiária do Programa Bolsa Família trabalha (CAMPELLO, 2013). Informação confirmada no estudo de Freguglia, Kern e Vieira (2018) sobre a oferta de trabalho de adultos de 18 a 69 anos de idade. Os autores concluíram que não há impacto significativo do PBF sobre a oferta de trabalho dos beneficiários, no que diz respeito a participação na força de trabalho e no total de horas trabalhadas. Contudo a sua inserção no mundo do trabalho, como será exposto adiante, é 
em geral precária, com renda baixa e instável. Soares e Sátyro (2009) mostraram que, enquanto a taxa de participação no mercado de trabalho dos beneficiários do PBF é de $74 \%$, a dos não beneficiários é de $68 \%$. Para eles, isto se explica pelos baixos valores transferidos pelo programa, os quais estão a uma distância significativa do salário mínimo, não se tornando, portanto, um motivo para que o beneficiário deixe de trabalhar.

Conhecer a face da pobreza atendida pelo PBF é possível através do perfil dos beneficiários. Aqui será possível entender que há um grupo extremamente fragilizado econômica e socialmente, para o qual é necessário o desenvolvimento e manutenção de ações de proteção social para que seja possível sanar, imediatamente, as emergências nutricionais e interromper o ciclo geracional da fome e da pobreza. A pobreza não é um fenômeno fixo. Sousa e Osório (2013) afirmam que, com o passar do tempo, ocorrem variações no número e percentual de pobres, assim como em suas características, além das mudanças em relação à entrada e saída de indivíduos e famílias deste grupo. Estudos e reelaborações periódicas dos perfis de pobreza são essenciais para a atualização dos diagnósticos correntes e para subsidiar as políticas públicas voltadas para os mais vulneráveis. Em geral, as pesquisas sobre os perfis de pobreza consideram características geográficas, demográficas, educacionais, ocupacionais entre outras.

Camargo (2013) apresenta o perfil das famílias beneficiárias do PBF que são compostas em média, por 3,6 pessoas sendo a maior parte $(50,2 \%)$ residentes no Nordeste do país, que antes de receberem o benefício, viviam na extrema pobreza $(72,4 \%)$. A predominância dos beneficiários do PBF no Nordeste e Centro-Oeste reflete o subdesenvolvimento econômico e tecnológico destas regiões, onde há o predomínio de atividades extrativistas e primárias. $\mathrm{O}$ arranjo familiar dos beneficiários se constitui, em sua maior parte, como monoparental feminino (42,2\%), seguido por casal com filhos (37,6 \%). Dado que deixa explícita a situação de imensa vulnerabilidade da mulher na medida em que não podem contar com outros adultos para a manutenção e o cuidado da família.

Ainda sobre as mulheres, as mais jovens enfrentam duas distorções do mercado de trabalho: as conhecidas barreiras para a sua entrada colocadas aos jovens em geral e os diferenciais de rendimento frente a um homem com o mesmo nível de instrução. Neste sentido, a oferta de serviços de creche e de políticas de emprego e qualificação para estas mulheres são de especial importância para que possam buscar a promoção da renda familiar.

Pesquisas e estudos empíricos têm demonstrado que, no Brasil, as muIheres, sobretudo as mais pobres, carecem não apenas de renda monetária, mas de serviços para ampliar sua autonomia no âmbito das relações sociais de gênero e expandir suas posições no mercado de trabalho, superando iniquidades de toda sorte e tornando possível o seu empoderamento (FRIAS; RAMOS, 2015). Provisão de creches, escolas tempo integral, centros de convivência intergeracionais são alguns dos serviços públicos capazes de favorecer a inserção produtiva feminina e, consequentemente, a redução da pobreza familiar (LAVINAS; NICOLL, 2006, p. 41). 
OS BENEFICIÁRIOS DO PROGRAMA BOLSA FAMÍLIA E O MERCADO DE TRABALHO: UMA ANÁLISE BIBLIOGRÁFICA SOBRE O "EFEITO PREGUIÇA"

Nas famílias mais vulneráveis, a presença do cônjuge no domicílio é muitas vezes incerta, como demonstram estudos antropológicos com famílias beneficiárias o que se refletem no incremento na participação de mulheres com filhos e sem cônjuge entre as famílias brasileiras, especialmente nas famílias de baixa renda (CAMARGO et al, 2013).Constanzi e Fagundes (2010) analisaram o perfil dos beneficiários e confirmaram o sexo feminino como maioria do total dos beneficiários do PBF em todas as regiões. Em relação à cor/raça, $65,3 \%$ dos beneficiários se declararam pardos e 7,5\% negros perfazendo um total de $72,8 \%$ ou quase três quartos dos beneficiários. Segundo os autores esta representação decorre do maior nível de pobreza da população parda/negra em relação à branca.

Para Chediek (2014, p. 670) o benefício do PBF empodera as mulheres ao constituí-las como portadores preferenciais do cartão do Programa Bolsa Família, o que vai ao encontro comprometimento do Brasil com os Objetivos do Milênio no que diz respeito à promoção da igualdade de gênero. As mulheres representam mais de $90 \%$ dos portadores de cartões, sendo quase $70 \%$ delas afrodescendentes. Essas mulheres têm utilizado os recursos em benefício de suas famílias desejando ver seus filhos educados e saudáveis, capazes de construir um futuro melhor para eles. Além do empoderamento das mulheres, impactos positivos de políticas como o Bolsa Família também foram verificados na redução das diferenças sociais e econômicas existentes entre os grupos raciais no Brasil.

Na publicação Policy in Focus "Mulheres Protagonistas", do IPC-IG/ PNUD, Hermeto (2014) compara o poder decisório das mulheres brancas e negras em suas casas, com base nas despesas domésticas, educação dos filhos, emprego do cônjuge e uso de métodos contraceptivos. Os beneficiários do PBF estão em sua maioria (55\%) na base da pirâmide etária - pessoas entre 0 e 19 anos. Isto ocorre em todas as regiões do Brasil, evidenciando que as crianças de 0 a 9 anos respondem por mais de um quarto $(26,5 \%)$ dos beneficiários.

Além das questões do arranjo familiar, em relação à distribuição da pobreza destacamos a variável geográfica. Aqui fica clara a influência da imigração europeia no mapa da pobreza atual. Pode-se afirmar que a imigração europeia influenciou as diferenças regionais da pobreza, sendo que a região Sul apresenta maior proporção de pessoas que se declaram brancas $(76,3 \%)$. As pessoas declaradas negras encontram-se em maior percentual na região Sudeste $(10,4 \%)$ e no Nordeste $(7,3 \%)$. As declaradas pardas no Norte $(84,3 \%)$ e Nordeste $(76,1 \%)$. Em relação aos grupos amarelo e indígena, há percentuais baixos no Brasil (0,3\% e 0,7\%) (CAMARGO et al, 2013). Estes dados confirmam que a dinâmica da história do trabalho no Brasil, que será apresentada adiante, foi determinante para construção do atual cenário da pobreza e da exclusão social atual. Rejeitados pelos empregadores após a abolição da escravatura e a chegada de mão de obra europeia, o grupo populacional formado por negros e pardos carrega esta herança e constitui hoje praticamente três quartos dos beneficiários do PBF. Constanzi e Fagundes (2010) apresentam o impacto médio dos benefícios do PBF na renda per capita das famílias beneficiárias e chamam atenção para as regiões norte e nordeste. 
Outro fator determinante para a ocorrência de pobreza e pobreza extrema como consequência da exclusão do mercado de trabalho formal e/ou capacidade de trabalho é o nível de escolaridade. Este é muito baixo entre os beneficiários do PBF, sendo que mais de dois terços dos seus beneficiários (69\%) não possuem o ensino fundamental completo. A vulnerabilidade desta população, mais uma vez tem como exemplo marcante o Nordeste, onde $20,3 \%$ dos beneficiários com 25 anos ou mais são analfabetos (CAMARGO et al, 2013). As questões raciais, de gênero e as relacionadas à escolaridade e ao acesso a serviços de infraestrutura domiciliar devem ser trabalhadas na implementação de ações intersetoriais em todas as esferas federativas, na promoção de acesso a serviços e de inclusão produtiva da parcela mais vulnerável da população.

A renda do trabalho de uma família depende do acesso dos seus membros ao trabalho e da qualidade dos postos que ocupa. Assim é de pouca utilidade para a formação da renda de uma família o acesso de seus membros a trabalhos de baixa produtividade ou a trabalhos em que apenas uma pequena parcela do que é produzido pelo trabalhador é por ele recebida. A produtividade do trabaIho é determinada pela qualificação dos trabalhadores e qualidade dos postos de trabalho (BARROS, 2004). Neste caso, especificamente, cabe atentar para a escolaridade do responsável familiar que recebe o PBF: 52,1 \% deles declaram ter ensino fundamental incompleto e 12,1\% declaram-se sem instrução. Mais uma vez, a região Nordeste lidera com $16,0 \%$, cerca de duas vezes o encontrado nas regiões Centro-Oeste (8,6\%), Sul (7,1\%) e Sudeste (6,9\%). Esta condição afeta a inserção dos responsáveis familiares no mercado de trabalho, restringindo suas possibilidades de acesso a postos de trabalho que exigem qualificação e oferecem melhores rendimentos (CAMARGO, 2013). Isto faz com que precisem aceitar postos de trabalho degradantes, informais, temporários e/ou terceirizados, o que torna sua atividade laboral insegura e mal remunerada.

Apresentado o perfil do beneficiário do programa, pode-se inferir que embora disponível e disposto para o trabalho o público adulto do programa encontra obstáculos geográficos, de capacitação pessoal e de gênero para uma inserção laboral que poderia ser considerada digna de acordo com a Organização Internacional do Trabalho (2009). O que se comprova ao analisar as vulnerabilidades identificadas no perfil do grupo beneficiário:

a. a maioria dos beneficiários são moradores do Nordeste e do Centro-oeste, áreas predominantemente extrativistas e de atividades primárias (76\%), onde não há disponibilidade de outros tipos de postos de trabalho;

b. são em grande parte pardos/negros $(72,8 \%)$, herdeiros da cultura escravocrata do Brasil, cerceados nos seus direitos básicos de cidadãos desde o século XIX, moradores de áreas desprovidas de serviços sociais, principalmente de educação;

c. são jovens de 18 e 19 anos ainda sem cursos técnicos e/ou superior sem capacitação para inserção no mercado formal; 
OS BENEFICIÁRIOS DO PROGRAMA BOLSA FAMÍLIA E O MERCADO DE TRABALHO:

UMA ANÁLISE BIBLIOGRÁFICA SOBRE O "EFEITO PREGUIÇA"

d. mulheres chefes de família $(42,2 \%)$ possuem todas as dificuldades citadas nos itens anteriores acrescentado da tarefa de cuidar com os filhos o que limita o seu tempo de disponibilidade para o trabalho fora de casa.

Leichsenring (2010, p. 288) conclui que as trajetórias dos trabalhadores no mercado de trabalho formal tendem a ser mais instáveis quanto mais pobres forem os trabalhadores, que o tempo de vínculo empregatício desses trabalhadores inclina-se a ser mais curto e que, uma vez desligados do trabalho, possuem dificuldades para retornar. Consequentemente as variações de rendimento dos trabalhadores pobres são grandes, o que ocorre mesmo em um cenário econômico favorável, marcado pelo aumento da participação dos pobres no mercado formal de trabalho, conforme apresentou Pochmam (2012a, p. 22). Desta forma, para a população pobre e extremamente pobre, a existência de rendimentos provenientes do mercado formal de trabalho em um determinado ponto do tempo não é garantia de um fluxo estável de renda.

\section{Efeitos do benefício do PBF sobre a oferta de trabalho}

Conforme já apresentado por Campello (2013), a população beneficiária do PBF tem uma participação no mercado de trabalho formal maior do que a população não beneficiária. Brito (2011, p. 95) desenvolveu um estudo a partir da PNAD 2004, PNAD 2006 e Cadastro Único 2008 e concluiu que os beneficiários tendem a ter maior inserção no mercado de trabalho do que os não-beneficiários. Os estudos indicam que o efeito médio do PBF sobre a probabilidade de não trabalhar é pouco significante tanto para homens quanto para mulheres. Por outro lado, Teixeira (2011) afirma que há uma tendência para o aumento da possibilidade de trabalhar de 2,2\% para mulheres e de 1,6\% para homens, independente do valor da transferência.

Teixeira (2011) defende a ideia de que os baixos valores dos benefícios não sejam suficientes para gerar um efeito renda que anule o efeito potencial na probabilidade de trabalhar enquanto que a condicionalidade de frequência escolar pode, de fato, influenciar as mulheres na probabilidade de trabalhar. $\mathrm{Na}$ medida em que as crianças passam mais tempo na escola, aumenta a disponibilidade das mulheres para o trabalho. Para Tavares (2010, p. 630) "[...] o simples fato de deixar suas crianças na escola implica maior tempo disponível das mães para o trabalho, o que serve de mais um argumento para o efeito positivo do programa sobre a oferta de trabalho."

Bichir (2010, p. 124) apresenta as discussões de Medeiros, Brito e Soares (2007) que mostram que, apesar de o PBF representar em média um acréscimo de $11 \%$ na renda dos beneficiários, o valor recebido não é suficiente para que haja o desincentivo ao trabalho. Por outro lado, ela destaca que o dinheiro das transferências garante uma estabilidade de rendimentos que, por sua vez, 
permite a entrada em outros segmentos do mercado de trabalho mais vantajosos, estáveis e com melhor remuneração. Segundo a autora, Medeiros, Britto e Soares (2007) concluem que o argumento do desestímulo ao trabalho é mais baseado em preconceitos do que em evidências empíricas, apontando o caráter falacioso do argumento do "ciclo da preguiça" que seria gerado pelo PBF. As críticas também são descontruídas por Kerstenetzky (2009) que, com base em dados da PNAD 2006, aponta que a participação dos adultos no mercado de trabalho é maior entre os beneficiários do que no restante da população.

Teixeira (2011, p. 40) e Oliveira e Soares (2013) apresentam resultados de estudos que apontam a participação no PBF na redução de horas de trabalho semanais: para homens, redução de 0,56 horas de trabalho semanal (1,3\%), e 1,18 horas de trabalho semanal $(4,1 \%)$ para mulheres. Embora considerem os percentuais estatisticamente significantes reconhecem que eles não caracterizam o PBF como um desincentivo ao trabalho. A redução do trabalho feminino é previsível e aceitável devido a aspectos culturais relacionados à divisão das responsabilidades com o mercado e trabalho e o trabalho intradomiciliar. As mulheres dedicam 30 horas por semana em média para afazeres domésticos, enquanto os homens dedicam apenas 9 horas semanais. Por este motivo, as mulheres são mais sensíveis ao choque na renda e apresentam maior variação na oferta de trabalho.

Para os Medeiros, Britto e Soares (2007, p. 35), eventuais efeitos negativos sobre a oferta de trabalho para grupos específicos de trabalhadores não devem ter uma leitura necessariamente negativa. Famílias extremamente pobres tendem a intensificar a participação de mulheres, crianças e jovens no mercado de trabalho, quase sempre em ocupações precárias e mal remuneradas. Nestes casos, alguma redução da participação destes indivíduos no mercado laboral, devido ao recebimento do PBF, pode ser vista de maneira positiva. Mesmo com a constatação da possibilidade de alguma redução da participação das mães no mercado, é positivo inferir que estas estejam dedicando seu tempo para o cuidado com as crianças, o que pode garantir a redução da mortalidade infantil e a garantia do cumprimento das condicionalidades que visam interromper o ciclo intergeracional da pobreza. Os autores apresentam análise a partir de dados da PNAD 2004, os quais estimaram que a oferta de trabalho foi afetada positivamente pelo PBF em grupos de mulheres cônjuges, homens chefes e homens cônjuges. O estudo, que tinha como objetivo comparar beneficiários e não beneficiários com características semelhantes, concluiu que somente as mulheres chefes de família que recebem o benefício têm probabilidade menor de ofertar trabalho.

Jornadas semanais de trabalho mais curtas são característica de inserção precária e de acesso instável e irregular ao mercado de trabalho, o que tem como consequência a reprodução da pobreza. Essa restrição é mais desfavorável às mulheres: as mais pobres trabalham em média 26 horas por semana, 16 horas a menos que a média nacional e 11 horas a menos que a média feminina (LAVINAS; NICOLL, 2006, p. 48). Consequentemente é previsível e aceitável 
OS BENEFICIÁRIOS DO PROGRAMA BOLSA FAMÍLIA E O MERCADO DE TRABALHO:

UMA ANÁLISE BIBLIOGRÁFICA SOBRE O "EFEITO PREGUIÇA"

que o benefício do PBF diminua as horas de trabalho das mulheres enquanto que aumenta as horas dedicadas aos afazeres domésticos em 1,18 horas por semana, resultado que sugere que o PBF estimula a alocação do tempo em atividades que aumentam o bem-estar e o cuidado com os filhos, apesar de reduzir as horas de trabalho remunerado das mulheres (TEIXEIRA, 2011).

Tavares (2010, p. 630) partiu da PNAD 2004 para analisar o efeito do programa na decisão das mães beneficiárias em relação à sua jornada de trabalho. Escolheu como estratégia metodológica o método de propensity score matching e chegou a resultados que mostram que, embora o efeito renda seja negativo em relação às decisões de trabalho das mães, expresso pelo coeficiente associado ao valor do benefício, ele não parece ser suficiente para gerar o chamado "efeito-preguiça". Isto acontece porque o efeito do PBF sobre a decisão de trabalho das beneficiárias é positivo, uma vez que a condicionalidade do programa vinculada à educação, o qual exige das crianças frequência escolar de $85 \%$, pode motivar o efeito substituição no qual "[...]a mãe precisa trabalhar mais para compensar a perda da renda do trabalho no domicílio [...] o simples fato de passarem a frequentar a escola poderia reduzir o tempo que ficam em casa e que, portanto, necessitam de cuidados da mãe. " (TAVARES, 2010, p. 628). Neste caso, mesmo que os filhos não trabalhem, o tempo em que ficam na escola pode proporcionar à mãe mais tempo para o trabalho.

Apesar de o efeito ser negativo ao reduzir o número de horas de trabalho semanal, a elasticidade de horários ocorre em alguns tipos de ocupação, variando em dimensão e significado estatístico. As mulheres que trabalham por conta própria são as mais sensíveis ao recebimento das transferências do PBF: elas reduzem suas horas de trabalho em 2,1 horas semanais (7,3\%). Para os homens, o trabalho assalariado agrícola é o tipo de ocupação mais elástico, nele a transferência do PBF é responsável por reduzir 1,1 hora semanal (2,7\%). O que leva à constatação de que informalidade é um aspecto importante para determinar a elasticidade da oferta de trabalho (OLIVEIRA; SOARES, 2013, p. 350).

Teixeira (2011) contribui para a discussão ao lembrar que os adultos trabaIham em diferentes tipos de ocupação: formal, informal ou por conta própria. Além disso, cada tipo de ocupação oferece diferentes médias de taxa salarial; a jornada pode ter horas flexíveis ou fixas; alguns tipos são mais estáveis que outros. Estas características podem influenciar a elasticidade da resposta ao choque de renda. Ela enfatiza também que a composição da força de trabalho se distribui de forma desigual a partir das variáveis: gênero e tipos de ocupação. Trabalhadores formais são aqui definidos como aqueles portadores de carteira de trabalho assinada, militares e os que trabalham para o setor público. Trabalhadores informais são aqueles sem carteira assinada, não remunerados e empregados domésticos. Empregadores, aqueles que têm seu próprio negócio e aqueles que produzem para o próprio consumo foram classificados como conta própria.

Para Teixeira (2011) quando se trata do trabalho formal, as mulheres têm jornada de trabalho mais próxima à dos homens. Assim sendo, o choque 
provocado pelo aumento de renda não é suficiente para reduzir o número de horas que homens e mulheres realizam no mercado de trabalho, isto porque estes últimos possuem contratos de trabalho formais, direitos trabalhistas e estabilidade em termos salariais (OLIVEIRA; SOARES, 2013, p. 350). O mesmo aspecto não se verifica no trabalho informal ou por conta própria, nos quais, talvez por não existir uma carga horária preestabelecida, torna-se mais fácil adaptar a maior jornada de afazeres domésticos (não remunerados) com uma menor jornada de trabalho remunerado (TEIXEIRA, 2011, p. 40). No setor informal, como era de se esperar, há maior elasticidade com respeito ao benefício do que entre os trabalhadores formais.

Os programas de transmissão de renda possuem impactos pequenos sobre o mercado de trabalho, e que alguns destes impactos, como a redução da jornada de trabalho das mães e o aumento na probabilidade de trabalho para certos grupos, são positivos. Do ponto de vista das políticas públicas, pode-se afirmar, com muito embasamento, que não existe constatação empírica que sustente a hipótese de que haveria um efeito renda maior do que um efeito substituição (fenômeno que recebeu a alcunha de "efeito preguiça"), no caso destes programas (OLIVEIRA; SOARES, 2012, p. 30).

\section{0 mercado de trabalho para os trabalhadores pobres}

A apropriação do sentido atribuído ao trabalho no mundo contemporâneo é essencial para a análise da relação entre o beneficiário do PBF e o mercado de trabalho, com foco na possibilidade de ocorrer o efeito preguiça em consequência do recebimento do benefício financeiro. Os problemas atuais do mercado de trabalho no Brasil estão relacionados tanto à globalização dos mercados, aumento da competitividade entre países e empresas, reestruturação produtiva, inovações tecnológicas, inovações sócio organizacionais, flexibilização das relações de trabalho quanto ao passado escravocrata do Brasil, à concentração da terra e à ausência de reforma agrária.

Esta seção visa discutir as causas e fenômenos que fragilizam as relações de trabalho na base da pirâmide.

\subsection{Trabalho e inclusão social}

Como já visto, o mundo do trabalho sofre mudanças contínuas que são consequências da evolução das relações das pessoas com a sociedade e com os grupos sociais. Ao longo dos anos, o modelo de gestão trabalhista e das organizações vem sofrendo mudanças, assim como os modelos sociais e econômicos. A Organização Internacional do Trabalho (OIT) defende o direito de todos a um trabalho digno, entendido como o resumo das aspirações mínimas do ser humano no domínio profissional, abrangendo vários elementos: 
OS BENEFICIÁRIOS DO PROGRAMA BOLSA FAMÍLIA E O MERCADO DE TRABALHO:

UMA ANÁLISE BIBLIOGRÁFICA SOBRE O "EFEITO PREGUIÇA"

a. oportunidade para realizar um trabalho produtivo com uma remuneração equitativa;

b. segurança no local de trabalho e proteção social para as famílias;

c. melhores perspectivas de desenvolvimento pessoal e integração social;

d. liberdade para expressar suas preocupações;

e. organização e participação nas decisões que afetam as suas vidas;

f. igualdade de oportunidades e de tratamento para todas as mulheres e homens (ORGANIZAÇÃO INTERNACIONAL DO TRABALHO, 2009).

Longe de atender aos direitos dos trabalhadores defendidos pela OIT, os fenômenos que fragilizam as relações de trabalho na base da pirâmide fazem com que o trabalhador perca direitos e garantias sociais. Para Antunes (2012), tudo se converte em precariedade, sem qualquer garantia de continuidade. O trabalho precário se encontra em um limite incerto entre ocupação e não ocupação, não havendo o reconhecimento jurídico das garantias sociais em relação a ele. Para o autor, os fenômenos de flexibilização, desregulamentação das relações de trabalho e ausência de direitos fragilizam a força de trabalho na falta de garantias em relação ao futuro e à renda. Sen (2010, p. 36) afirma que a insegurança em relação ao vínculo do emprego vai além da deficiência de renda, ele defende que é uma fonte de efeitos debilitadores sobre a liberdade, a iniciativa e as habilidades dos indivíduos. Ele reafirma a ideia do desemprego como exclusão social para alguns grupos destacando como consequências deste a perda da autonomia, da autoconfiança e da saúde física e psicológica, minando a autoestima da pessoa.

Reconhecido como mecanismo de inclusão social, o trabalho é considerado o instrumento mais importante para a superação da pobreza e da extrema pobreza, os quais são fenômenos sociais dinâmicos que devem ser compreendidos a partir da condição específica de cada indivíduo ou de cada família. A precarização do mercado de trabalho e a informalidade contribuem para que as famílias mais pobres não encontrem modos de superar a pobreza. É neste contexto que o beneficiário do PBF acessa o mundo do trabalho.

Apesar da crise do trabalho, estudos apontam para a queda da desigualdade no Brasil. Os responsáveis pela pequena melhoria na distribuição de renda seriam, não apenas o comportamento favorável do mercado de trabalho na base da pirâmide social e os aumentos reais do salário mínimo, mas também os programas de transferência de renda. Segundo dados calculados com base na PNAD 2006, o mercado de trabalho teria uma participação de aproximadamente $80 \%$ neste resultado, enquanto os programas de transferência de renda complementariam esse percentual (HOFFMANN, 2013). As mudanças sociais estão interligadas às modificações na estrutura produtiva, com crescente impulso do setor terciário, sobretudo na geração de postos de trabalho. A grande maioria das ocupações abertas na década de 2000 concentrou-se nas de salário de base - ao redor do mínimo nacional, ou seja, dos 2,1 milhões de vagas abertas por 
ano, em média 2 milhões estão na faixa salarial de 1,5 salários mínimo mensal e absorvem grandes parcelas de trabalhadores na base da pirâmide social reduzindo sensivelmente a taxa de pobreza no Brasil (POCHMANN, 2012a, p. 22).

Partindo da caracterização do mercado de trabalho atual no Brasil e suas especificidades e considerando o incentivo do Estado para a capacitação dos trabalhadores pobres e extremamente pobres - políticas de inclusão produtiva e a prioridade em criar postos de trabalho para ocupar a população da base da pirâmide social do Brasil - os próximos passos serão apresentar os trabalhos dos pobres e extremamente pobres e o perfil do beneficiário do programa, para que seja possível finalmente a revisão dos estudos acerca da ocorrência ou não do "efeito preguiça", que causaria o desestímulo ao trabaIho dos beneficiários adultos do PBF.

A disponibilidade de oferta de postos de trabalho está vinculada à dinâmica do mercado de trabalho. Neste, as pessoas oferecem sua força de trabalho àqueles que precisam dela, em um sistema onde se negociam preço e trabalho a partir da lei da oferta e da procura. Pode-se afirmar que, quando existe oferta em excesso de trabalhadores e uma procura constante e/ou diminuída, não há equilíbrio entre oferta e procura. Soma-se a isto que, de uma forma geral, postos de trabalho no mercado formal exigem habilidades e competências específicas às quais são desenvolvidas a partir de treinamento, capacitações e formação educacional, aos quais a população pobre e extremamente pobre não tem acesso. Atualmente, no Brasil, são recorrentes situações em que sobram postos de trabalho para os quais são necessários trabalhadores capacitados, ao mesmo tempo em que há um grande número de desempregados não capacitados.

A grande oferta de trabalhadores com baixa ou nenhuma escolaridade obriga que muitos acabem por aceitar quaisquer oportunidades de trabalho. Muitas vezes, o trabalhador pobre ou extremamente pobre é obrigado a atuar em postos de trabalho em condições consideradas degradantes e/ou análogas ao trabalho escravo. Estes postos de trabalho estão na agricultura, indústria e construção civil. Os trabalhadores são aliciados também para trabalhar em carvoarias, laranjais, canaviais, fazendas de frutas e algodão e para pequenas tecelagens e canteiros de construção no meio urbano.

Além das limitações impostas pelo mercado de trabalho formal para a população pobre e extremamente pobre, o brasileiro é empreendedor. "Pesquisa de Perfil do Empreendedor Individual elaborada pelo Sebrae em parceria com o Ministério do Desenvolvimento Social e Combate à Fome (MDS) mostrava que, em 31 de julho de 2011, havia 102.627 MEls beneficiários do PBF, o que representava 7,3\% do total de MEls à época. " (SEBRAE, 2011). O que nos conduz para a próxima sessão.

\subsection{O microempreenderismo entre os beneficiários}

Apesar de não existir comprovação de um efeito renda maior que um efeito substituição, os beneficiários do programa têm, como já visto, a inser- 
OS BENEFICIÁRIOS DO PROGRAMA BOLSA FAMÍLIA E O MERCADO DE TRABALHO:

UMA ANÁLISE BIBLIOGRÁFICA SOBRE O "EFEITO PREGUIÇA"

ção no mercado de trabalho formal dificultada por diversos fatores. O grupo em questão vive em constante insegurança em relação à disponibilidade de postos de trabalho e variação de renda. Situação que promove exclusão social e mina a autoconfiança e a saúde física e psicológica da pessoa.

Diante da falta de alternativas, o Programa das Nações Unidas para o Desenvolvimento aponta que muitas pessoas procuram o chamado auto emprego (PROGRAMA DAS NAÇÕES UNIDAS PARA O DESENVOLVIMENTO, 2004). Oliveira (2013) afirma ainda que, estimular o surgimento de micro, pequenas e médias empresas tem sido uma estratégia eficaz na geração de emprego e renda. E demonstra que governos, organizações públicas e privadas de fomento e instituições de ensino profissionalizante e de ensino superior têm efetuado esforços para propiciar o surgimento destes negócios.

A Lei Complementar (LC) n. 128/2008 criou a figura do microempreendedor individual (MEI) com a intenção de dar condições mais justas para que miIhões de empreendedores saiam da informalidade. Em dois anos foram cerca de 2,8 milhões de microempreendedores individuais formalizados de acordo com pesquisa do Serviço Brasileiro de Apoio às Micro e Pequenas Empresas (Sebrae) em 2011. Além dos empreendedores que estavam na informalidade, a lei tornou possível que muitas pessoas, antes desempregadas, identificassem a possibilidade de auto sustento por meio do empreendedorismo (MOREIRA, 2013).

A figura do microempreendedor individual ganhou relevância em 2011 quando o governo lançou o Plano Brasil sem Miséria com foco na assistência às pessoas extremamente pobres. Naquele momento, além das transferências de renda e do acesso aos serviços públicos, já existentes no PBF, surgiu a iniciativa de promover a inclusão produtiva, da qual o microempreendedorismo individual foi uma das ações. A Pesquisa de Perfil do Empreendedor Individual elaborada pelo Sebrae (2011) em parceria com o Ministério do Desenvolvimento Social e Combate à Fome (MDS) mostra que, em 31 de julho de 2011, existiam 102.627 MEls beneficiários do PBF, o que representava 7,3\% do total de MEls na época. Os MEls beneficiários do PBF (MEls-PBF) estão concentrados: $41 \%$ deste público encontra-se na região Nordeste; $32 \%$, no Sudeste; $10 \%$, no Norte; $10 \%$, no Sul; e $8 \%$ no Centro-Oeste. Percentuais que comprovam a busca dos beneficiários da região Nordeste, onde há menor oferta de postos de trabalho, pelo auto emprego, o que mais uma vez comprova a disposição e disponibilidade do beneficiário para o trabalho.

Com relação ao gênero, constata-se que um pouco mais da metade $(50,2 \%)$ dos microempreendedores individuais beneficiários do Programa Bolsa Família são do gênero feminino. Além de muitas das atividades permitidas pela LC no 128/2008 serem tradicionalmente ligadas às mulheres, o fato de pessoas do sexo femininos, muitas vezes sem cônjuge, serem, predominantemente, as chefes das famílias beneficiárias do PBF pode estar relacionado a esta participação feminina mais forte (HOW, 2010 apud MOREIRA, 2013). Quando observados os dados de grau de parentesco com o responsável da fa- 
mília desses microempreendedores individuais, vê-se que praticamente metade (50\%) destes MEls são os próprios responsáveis. Em seguida, vêm os cônjuges ou companheiros, com 39\%. Outra percentagem que pode ser ressaltada é que $7,4 \%$ dos MEls-PBF são filhos dos chefes de família. Este dado condiz com um dos objetivos do PBF de quebrar o ciclo intergeracional da pobreza. Com relação à faixa etária desses empreendedores, percebe-se uma concentração nas idades entre 25 e 39 anos, que contemplam $56 \%$ dos MEls-PBF. Esta distribuição não difere muito da dos microempreendedores individuais, em geral, apenas com uma menor incidência de menores de 24 anos e de maiores de 40 anos.

Comparando-se a escolaridade dos MEls-PBF com a dos MEls em geral, vê-se uma predominância maior dos que possuem educação em nível de ensino fundamental completo ou incompleto. Enquanto 60\% dos MEls-PBF encontram-se nesta faixa, apenas $36 \%$ do total de MEls têm este nível de escolaridade. Percebe-se também uma menor incidência de ensino médio ou técnico completo ( $39 \%$ versus $47 \%$ ) e ensino superior - $1 \%$ dos beneficiários do Bolsa Família microempreendedores individuais. Brito e Kerstenetzky (2011) afirmam que $78,5 \%$ dos beneficiários do PBF não complementaram o ensino fundamental. Logo, os MEls-PBF têm uma escolaridade menor que a média dos MEls, mas, ainda assim, maior que a dos PBF em geral. Se, por um lado, é esperado que os MEls beneficiários do PBF tenham uma escolaridade menor que a dos MEls em geral - afinal, são mais pobres -, por outro, chama a atenção o fato de eles serem mais escolarizados que a média dos beneficiários em geral.

Na Pesquisa de Perfil do Empreendedor Individual (SEBRAE, 2011), há uma questão a respeito da ocupação desempenhada pelo microempreendedor individual logo antes de se formalizar. Fazendo-se um recorte dos que, também na pesquisa, responderam que recebiam Bolsa Família até seis meses antes de se formalizar. Entre os MEls-PBF, $55 \%$ já possuíam um negócio informal (em contraposição a $57 \%$ do total de MEls) e $10 \%$ estavam empregados sem carteira. O que mais se destaca, porém, é a percentagem de desempregados que se tornaram microempreendedores individuais. Enquanto, no universo de MEls, $12 \%$ estavam desempregados antes de se formalizar, este número salta para $23 \%$ entre os MEls que recebiam Bolsa Família. Isto parece mostrar o potencial do empreendedorismo formal como ferramenta de inclusão produtiva, mas também levanta a questão da precarização das relações de trabalho.

Percebe-se aqui a necessidade de manter e reforçar os mecanismos de comunicação do governo divulgação para esclarecer os mais pobres e menos escolarizados acerca dos benefícios de se formalizar, ação que deve ser acompanhada de apoio estatal de assistência social e capacitação técnica e financeira, pois o auto emprego através do empreendedorismo formal apresenta-se como uma alternativa para o problema de desemprego da população pobre. Porém, ela não é suficiente para substituir os empregos em empresas maiores, onde, devido à maior produtividade advinda da maior intensidade de capital, 
OS BENEFICIÁRIOS DO PROGRAMA BOLSA FAMÍLIA E O MERCADO DE TRABALHO:

UMA ANÁLISE BIBLIOGRÁFICA SOBRE O "EFEITO PREGUIÇA"

costumam também existir salários melhores. A dificuldade é que, como veremos a seguir, a população pobre é constantemente subjugada por um mercado de trabalho que historicamente destina a ela postos de trabalho precários, inseguros e mal remunerados.

\section{Considerações finais}

Os efeitos do benefício do PBF sobre a disposição para o trabalho dos beneficiários e as possibilidades de desenvolver autonomia econômica através da inclusão produtiva são constantemente questionados. Declarações destituídas de evidência empírica afirmam que o PBF estimula o "efeito preguiça" entre os beneficiários, porém segundo a Pnad 2011, entre as famílias com rendimento mensal per capita de até $1 / 4$ do salário mínimo (as mais pobres), $62 \%$ da renda familiar é proveniente do trabalho. Este dado corrobora as informações do Cadastro Único do Governo Federal, de que a maioria da população pobre e beneficiária do programa de fato trabalha. Entretanto, são em sua maioria trabalhos precários e informais (ABRAMO; RIBEIRO, 2013) e consequentemente inseguros, como foi possível constatar nesta pesquisa.

Sobre a disponibilidade e disposição para o trabalho, os estudos comprovam que as variações constatadas nas pesquisas, embora estatisticamente significativas não são suficientes para justificar a tese generalizada de que o benefício do PBF desestimula a oferta de trabalho entre os beneficiários. As condições demográficas, de raça, gênero e educacionais têm mais impacto sobre a ocupação de postos de trabalho do que o benefício do programa em si.

A partir da análise dos resultados pesquisados constata-se que as variações de oferta de trabalho ocorrem principalmente entre as beneficiárias chefes de família que atuam no mercado informal, cujas atividades na maior parte das vezes são precárias, instáveis e irregulares. Para elas o benefício possibilita a escolha de diminuir em algumas horas o tempo dedicado para o trabalho, substituindo-o pelo cuidado com os filhos, o que não é uma situação que mereça ser chamada de preguiça. Por outro lado, a inclusão produtiva com foco no empreendedorismo, visa oferecer uma opção de ocupação e de renda para os beneficiários do PBF através da formalização, por meio da figura do microempreendedor individual, trabalhadores autônomos que recebem benefícios do Programa Bolsa Família e apoiar aqueles beneficiários do programa já formalizados como MEls.

Diante do cenário apresentado fica claro o papel do trabalho digno como mecanismo de inclusão social e de superação da pobreza e da pobreza extrema. Situações precárias e inseguras de trabalho fragilizam a população pobre e extremamente pobre contribuindo para que não encontrem modos de superar suas vulnerabilidades sociais. Estas são questões fundamentais que vão além do preconceito do "efeito preguiça" e contextualizam verdadeiramente o acesso do beneficiário do PBF ao mundo do trabalho. 


\section{Referências}

ABRAMO, Laís; RIBEIRO, José. Uma década de Bolsa Família: efeito preguiça é mito. 2013. Disponível em: http://bolsafamilia10anos.mds.gov.br/node/183. Acesso em: 04 abr. 2015.

ANTUNES, Ricardo. As formas contemporâneas de trabalho e a desconstrução dos direitos sociais. In: SILVA E SILVA, Maria Ozanira da; YAZBEK, Maria Carmelita (Orgs.). Políticas públicas de trabalho e renda no Brasil contemporâneo. São Paulo: Cortez, 2012. p. 37-58.

BARROS, Ricardo Paes de. Acesso ao trabalho e produtividade no Brasil: implicações para crescimento, pobreza e desigualdade. Rio de Janeiro: IPEA, 2004.

BICHIR, Renata Mirandola. O Bolsa Família na berlinda? Os desafios atuais dos programas de transferência de renda. Novos Estudos, n. 87, 2010.

BRASIL. Lei N. 10.836, de 9 de janeiro de 2004: cria o programa Bolsa Família e dá outras providências. In: Caderno de orientações e legislação do Programa Bolsa Família e Cadastro Único: informações importantes para a gestão municipal. Brasília, 2013b.

BRITO, Alessandra Scalioni; KERSTENETZKY, Célia Lessa. Beneficiários do Bolsa Família e mercado de trabalho: considerações metodológicas e substantivas. Rio de Janeiro: CEDE-UFF, 2011. Disponível em: <http://www. proac.uff.br/cede/sites/default/files/TD21_1.pdf>.

CAMARGO, Camila Fracaro et al. Perfil Socioeconômico dos Beneficiários do Programa Bolsa Família: o que o Cadastro Único Revela? Centro Internacional de Políticas para o Crescimento Inclusivo, n. 240, 2013.

CAMPELLO, Tereza. Uma década derrubando mitos e superando expectativas. In: CAMPELLO, Tereza; NERI, Marcelo Côrtes. Programa Bolsa Família uma década de inclusão e cidadania. Brasília: IPEA, 2013.

CHEDIEK, Jorge. Brasil Sem Miséria: a transformação na vida de milhões de brasileiros e brasileiras In: BRASIL. Ministério do Desenvolvimento Social e Combate à Fome. O Brasil sem miséria. Brasília: MDS, 2014.

COSTANZI, Rogério Nagamine; FAGUNDES, Flávio. Perfil dos beneficiários do Programa Bolsa Família. In: CASTRO, Jorge Abrahão de; MODESTO, Lúcia. (Orgs.) Bolsa Família 2003-2010: avanços e desafios. Brasília: Ipea, 2010. v. 1, p. 249-270.

FONSECA, Ana; FAGNANI, Eduardo (Orgs.) Políticas sociais, desenvolvimento e cidadania: educação, seguridade social, pobreza, infraestrutura urbana e transição demográfica. Fundação Perseu Abramo, n. 3, abr. 2015.

FRIAS, Lincoln; RAMOS, Patrícia. El Programa Bolsa Famílią aumenta el poder de decisión de las mujeres en el hogar? Revista Debate Econômico, v. 2, n. 2, 2015, p. 53-65.

FREGUGLIA, Ricardo da Silva; KERN, Ana Paula; VIEIRA, Marcel de Toledo. Impacto do programa bolsa família na oferta de trabalho dos beneficiários. In: ENCONTRO NACIONAL DE ECONOMIA, 46., 2018, Rio de Janeiro. Anais [...] Rio de Janeiro: ANPEC, 2018. Disponível em: https://www.anpec.org.br/encontro/2018/ submissao/files_l/i13-0067d7849ac13f746bba8538313776d3.pdf. Acesso em: 28 jun. 2019.

HERMETO, Ana. Avaliação do Programa Bolsa Família: uma Perspectiva de Gênero e Raça. Policy in focus, n. 27, mar. 2014. p. 29-33.

HOFFMANN, Rodolfo. Transferência de renda e desigualdade no Brasil (1995 - 2011). In: CAMPELLO, Tereza; NERI, Marcelo Côrtes. Programa Bolsa Família uma década de inclusão e cidadania. Brasília: IPEA, 2013.

KERSTENETZKY, Célia Lessa. "Redistribuição e desenvolvimento? A economia política do Programa Bolsa Família". Dados, Revista de Ciências Sociais, 2009, vol. 52, nº 1, pp. 53-83.

LAVINAS, Lena; NICOLL, Marcelo. Pobreza, transferências de renda e desigualdades de gênero: conexões diversas. Parcerias estratégicas, n. 22, jun. 2006. (Edição Especial).

LEICHSENRING, Alexandre R. Precariedade laboral e o programa bolsa família. In: CASTRO, Jorge Abrahão de; MODESTO, Lúcia (Orgs.). Bolsa Família 2003-2010: avanços e desafios. Brasília: Ipea, 2010. Volume 1. 
OS BENEFICIÁRIOS DO PROGRAMA BOLSA FAMÍLIA E O MERCADO DE TRABALHO:

UMA ANÁLISE BIBLIOGRÁFICA SOBRE O "EFEITO PREGUIÇA"

MEDEIROS, Marcelo; BRITTO, Tatiana; SOARES, Fábio. Transferência de renda no Brasil. Revista Novos Estudos, v. 79, p. 5-21, 2007.

MOREIRA, Rafael de Farias Costa. Empreendedorismo e inclusão produtiva: uma análise de perfil do microempreendedor individual beneficiário do Programa Bolsa Família. Radar: Tecnologia, Produção e Comércio Exterior, n. 25, p. 19-32, abr. 2013.

OLIVEIRA, Luís Felipe Batista; SOARES, Sergei S. "Efeito preguiça" em programas de transferência de renda? In: CAMPELLO, Tereza; NERI, Marcelo Côrtes. Programa Bolsa Família uma década de inclusão e cidadania. Brasília: IPEA, 2013.

OLIVEIRA, Luís Felipe Batista de; SOARES, Sergei S. D. O que se sabe sobre os efeitos das transferências de renda sobre a oferta de trabalho. Brasília: IPEA, 2012. (Texto para discussão, 1738).

ORGANIZAÇÃO INTERNACIONAL DO TRABALHO. Estabelecer Padrões de Segurança Social. Editada GEP/MTSS, 2009

POCHMANN, Marcio. Rumos da política do trabalho no Brasil. In: SILVA E SILVA, Maria Ozanira da; YAZBEK, Maria Carmelita (Orgs.). Políticas públicas de trabalho e renda no Brasil contemporâneo. São Paulo: Cortez, 2012a. p. 37-58.

PROGRAMA DAS NAÇÕES UNIDAS PARA O DESENVOLVIMENTO. Relatório do desenvolvimento humano: 2004: Liberdade Cultural num Mundo Diversificado. Lisboa: 2004.

SEBRAE. Pesquisa de perfi I do empreendedor individual: 2011. Brasília, 2011.

SEN, Amartya. Desenvolvimento como liberdade. São Paulo: Companhia de Bolso, 2010.

SOARES, S.; SÁTYRO, N. O programa Bolsa Família: desenho institucional, impactos e possibilidades futuras. Brasília: Ipea, 2009. (Texto para Discussão, n. 1.424).

SOUZA, Pedro Herculano Guimarães Ferreira de Souza; OSÒRIO, Rafael Guerreiro. O perfil da pobreza no Brasil e suas mudanças entre 2003 e 2011. In: CAMPELLO, Tereza; NERI, Marcelo Côrtes. Programa Bolsa Família uma década de inclusão e cidadania. Brasília: IPEA, 2013.

TAVARES, Priscilla. A. Efeito do Programa Bolsa Família sobre a oferta de trabalho das mães. Economia e Sociedade, Campinas, v. 19, n. 3 (40), p. 613-635, dez. 2010.

TEIXEIRA, Clarissa Gondim. Efeitos da transferência de renda na oferta de trabalho. Mercado de trabalho, IPEA, n. 46, fev. 2011. (Nota técnica). 